\title{
Teachers' Training Strategy of Local Colleges and Universities
}

\author{
HongLang. Li ${ }^{1, a}$, Xiao. $\mathrm{Li}^{1, \mathrm{~b}}$ \\ ${ }^{1}$ Jiangxi Science \& Technology Normal University, Nanchang, Jiangxi, 330013, P.R. China \\ aLiHonglang2013@163.com, 'Xiaoli2015@126.com
}

Keywords: Backbone teachers, teacher management, Training Strategy

\begin{abstract}
China's higher education is in an unprecedented period of development. Country attaches great importance to the development of local institutions of higher education, because it is local economic development, transport a large number of businesses in urgent need of talent. Priority is to strengthen the development of local higher education institutions where teaching team building, improve the overall quality of teachers, especially the backbone teacher training. This paper analyzes the current situation of the backbone of the local teachers' colleges, there is a problem in terms of identification, cultivation, cultivation strategy proposed local backbone teachers colleges.
\end{abstract}

\section{Introduction}

With the rapid development of information technology and the rapid spread of computer networks, especially the rapid popularization of mobile networks, QQ, micro letters, e-mail and a variety of APP application has gradually integrated into the lives of college students, college students gradually became college life part, changing lifestyle of college students learning to students bring a lot of convenience, but also bring a range of psychological problems, can not be ignored. Strengthening college students' mental health records, monitoring students' psychological changes, to guide the growth of students' mental health is an important work in colleges and universities to strengthen the mental health education.

\section{Importance of Teachers' Training}

Teachers are the backbone of the construction of universities, especially in key Construction of Teachers in Higher Vocational College. Stabilize the backbone of the general release, the team will be able to reach the normal flow of good posture.

The key lies in the construction of the backbone of teachers in training young teachers. The young teachers to train and cultivate a new generation of academic leaders is the current and future period universities, especially important and difficult construction of teachers colleges, how to do better still worth exploring.

Backbone teachers teaching behavior directly and indirectly affect the other teachers, they are role models, high-recognized degree. Especially for new teachers, role models backbone teachers are endless.

Management "Pareto theory" that a unit or enterprise is often from $20 \%$ to $80 \%$ of the backbone to complete the task. With the advent of the era of knowledge and information, the teacher labor is relatively closed, not high degree of shared state is gradually broken, building schools open, key teachers burden-sharing, broader commitment to the service of teaching and research will be possible, the backbone of teachers the demonstration, radiation will be further highlighted.

\section{Cadre Teacher of local colleges}

Local colleges and universities teachers in the prevalence of teacher self-centered, very lack of communication between teachers; teachers besides teaching, the school for the rest of the job requirements is not enough strength in scientific research, including research, including the cause lack of enthusiasm and interest. This makes the whole teachers too little cooperation in business, the 
lack of a modern enterprise in a very important team spirit. The companies emphasized teamwork construction of university teachers is a great reference.

Young teachers is to build a team of the soul, is the leading pack interdisciplinary teaching and research, the beam of school education. Therefore, strengthening the cultivation of young teachers to enable them to further improve the moral and professional quality, proactive, committed to innovation, driven by the important task of cultivating young talent and the development of school education has important and far-reaching significance.

\section{The main problems that exist in Teachers' Training}

Construction of College Teachers must comply with the law of development of higher education Higher education and development of the situation, this work has an important influence on young teachers in training.

\subsection{The existence of young teachers' seniority light weight performance "phenomenon in the selection}

"Seniority light weight performance" is young teachers in the selection of the problems most vulnerable, "the capacity \& performance" based on the evaluation of scientific talent is the current trend, but seniority common phenomenon in many colleges and universities are still artificially many set threshold, leading to practical work and outstanding ability in teaching people the value of the column backbone fails, the teachers are not fully demonstrated, seriously dampened the enthusiasm of these people is not conducive to talent, expertise and resources situation formation.

\subsection{Young teachers' re-introduction, light training "and" re-use, light training "serious}

The backbone of the training of young teachers is a long-term work system, but one-sided emphasis on the introduction and use of teachers, teacher training neglect phenomena abound in most vocational colleges (such as some universities to pursue profit-oriented school the short leaps and bounds, by introduce teachers to achieve the integration, but the teacher did not pay attention to the introduction of long-term culture, and even part of the school as a result of a shortage of teachers, the backbone of teachers believe there is no need to attend the training and the necessary training, which leads to continued training young teachers are severely constrained .

4.3 Young teachers to grow, develop and create an environment and atmosphere is not enough

Teacher groups filled with "Jixianduneng" of the gas, the environment is not enough loose backbone teachers, leaders have not paid enough attention, there is no time for these key teachers to showcase your talent, do not provide demonstration and radiation for these key teachers of space (which is caused by key teachers to fend for themselves in the most direct and most important reason.

\section{Explore young teachers training model}

5.1 Young teachers should use in combat readiness and training to understand and, in the selection to be eclectic, the treatment should favorably, from thick.

For young teachers should adopt the attitude of concern and care, to provide space for the development of truly outstanding young talent, in terms of technical positions, and treatment should be exceptional promotion (in the selection of young teachers should have academic restrictions, especially in vocational schools, creative work as long as the education, practice and research operations, schools can receive praise, study research to create economic and social benefits, directly or indirectly, in the community, they should treat them as the backbone of teachers to develop Meanwhile, in terms of housing, the allowance given to young teachers to take care of, so that they will focus more on education for teaching and research, in order to better serve the schools and social services.

The selection of key teachers should adhere to the following principles: (1) backbone teachers should have good health and good charisma; (2) there is a strong teaching ability and innovation consciousness; (3) there is a strong teaching and research capabilities and performance; (4) guidance, influence, infecting other teachers charm, ability and enthusiasm. Selected seedling culture is 
important, but more important to the work of training into effect. Personnel training project in some schools and departments to pay more attention to the selection, but there is no specific training measures. Published on the list after the election, to cultivate a small amount of living allowance object, such an honor, such training is not effective.

We believe that: the backbone of teacher training should adhere to the following points: (1) there must be a clear training objectives and tasks, specific plans, and improve the management of assessment methods; (2) training conducted in conjunction with the construction of key disciplines, to have funds and other conditions support; (3) the school should continue to create good software and hardware environment to enhance training effectiveness.

Jiangxi Science and Technology Normal University in this regard to make a useful exploration and research. Jiangxi Science and Technology Normal University, Ministry of Education to meet the current needs assessment, academic leaders are fully aware of the core disciplines of academic echelon, training young academic backbone is the foundation of creating academic leaders, on the one hand emphasis on discipline construction, on the other hand more attention construction of teachers, especially the backbone teacher training, school since last year has been the selection of two groups of academic leaders identified. And most importantly, in terms of teaching, research, construction materials, and other disciplines to develop academic leaders made stringent requirements: (1) requires an annual academic leaders must Speaker main courses, students can combine classroom situation, students and teachers in the classroom situation interactions with the business line of communication for lesson plans, training direction, way, way constructive reform program. Lesson plans, training programs, the idea is not static, it is very important. (2) requires an annual academic leaders have presided over a teaching and research projects. Research is very important that teachers, especially teachers, academic leaders must always have a positive attitude research study of lesson plans, teaching methods research, research on teaching content for students to study psychology. The most important thing is to cultivate academic leaders in the implementation of dynamic management. Specific management measures are implemented rolling in the training process, focusing on actual performance, survival of the fittest. Schools competent authorities regularly check the implementation of planned measures, and organize an annual expert in the discipline and related disciplines to conduct a comprehensive examination and evaluation, to adjust, update and develop training plans.

\subsection{With "people-oriented" philosophy of education to train young teachers}

Improvement "re-introduction, light training" and "heavy use, light train" tendency, it is necessary to introduce the cultivation, use and cultivate young teachers to introduce us to combine high-quality teachers, but do not think that "a monk good chanting, "also based on the school train young teachers to provide opportunities for young teachers to improve education and enable young teachers to regular foreign exchange and learning, in order to broaden their horizons and improve their professional level, give full play to the backbone exemplary role of teachers to better meet the needs of the modern school education and teaching development.

Young teachers in training to be a scientific and reasonable increase or adjust their qualifications, knowledge and ability to structure, young teachers to continuously improve the level of business and academic levels.

Academic level and operational level is an important indicator of teaching staff, for the low education levels of young teachers, schools should create opportunities to encourage teachers to further their studies in master's and doctoral students, had just left for school teachers doctorate degree, to increase training to enable them to receive training expertise and practical experience, please some well-known experts and professors as tutors young teachers, to develop more detailed training program, a clear training objectives, so that they can quickly grow professionally

Young teachers to improve the knowledge of the structure: Modern vocational education not only requires teachers to have a broad base of expertise, but also to have some knowledge of related interdisciplinary fields. 


\subsection{Local school management training young teachers}

Teachers integrity of their own development, including five German, ability, diligence, and achievements, body, etc., if the development of a particular aspect of limited or no focus on a particular aspect of the building, will affect the overall development of teachers. So, when we plan to develop young teachers from the German culture, energy, five diligence, and achievements, full body start to nurture talent.

For young teachers of management principles: a detailed training program, training targeted. Backbone teachers made my own stated objectives, the specific functions of the department responsible for the audit carried out after careful arrangements, and make it clear that ultimately the young teachers in accordance with established training program is expected to complete the training objectives. In accordance with established training programs and objectives, functions for every young teacher regular assessment, does not meet the stated objectives of the teacher training program to produce "yellow card" on the over-achieve the stated objectives and the outstanding contributions of young teachers are awarded .

\subsection{Excellent team building can not be ignored}

Backbone teachers and academic leaders team status, direct and long-term impact on the functioning of colleges effect, so it is important to focus on training., The young teachers are part of the teachers, on the one hand there is no old teacher training and pass, to help with, the team could not grow quickly; the other team is not a source of water, but by young teachers grow replenished. Therefore, to enhance training young teachers did not ignore other teacher training.

Jiangxi Science and Technology Normal University academic leaders in the training process has been fully aware of the importance of team-building, and to emphasize that the training program in academic leaders: academic leaders must guide the young teacher teaching (including teaching methods, teaching ideas, writing lesson plans, etc.), the most important is the academic leader of the research projects must have a young teacher involved, so that these young teachers personally feel this research atmosphere, so that they have the opportunity to directly face to face with the research academic leaders to communicate.

In addition, in order to ensure the healthy growth of the entire team, our school also attaches great importance to training of young teachers.

(1) The importance of young teachers cultivate practical ability. First, the requirement to have a good young teachers teaching off, in addition to teaching young teachers a clear effort to be completed and reach the level, but also through the exchange of teaching experience from time to time held, the organization of teaching school teachers observe and lectures race, class above the competition, courseware competitions of young teachers to improve teaching practice and level of ability. Second, the development of young teachers to participate in professional courses of professional practice and training requirements, and ask them at least every three years, six months to the grassroots to participate in professional practice and training. Third, the arrangement of young teachers to participate in laboratory construction of specialized courses of young teachers also arrange production practice guidance, experimental study research projects, site commissioning of the production process, so that young teachers with a strong practical skills and solve practical problems of production capacity.(2) to accelerate young teachers to update their knowledge. Our school based on professional development, curriculum development and academic development needs through work practices and various forms of advanced studies and academic exchanges, so that young teachers to broaden the knowledge of related disciplines to master cutting-edge information, and to focus attention on foreign language training and computer training application ability, for most young teachers must be able to skillfully master and use the computer.

\section{Conclusion}

Article backbone of local teachers college status, role, status quo and problems were analyzed, and put forward their own views Training Strategy institutions where young teachers. This paper is "the backbone of the new and old teachers college Comparative Study" (Jiangxi Province Education 
Science "Twelfth Five Year Plan" focus on three topics year 2014, number: 14ZD3L016) one of the research results.

\section{References}

[1] Had Ze Xin Wen Yi Ai research students psychological records management system feedback mechanism [J]. Guangxi College of Education, 2007 (6).

[2] Wang Xiaoqi, Wang Xueying. Mental Health Survey and filing Problems and Countermeasures [J]. Psychology, 2011 (10).

[3] Jin Zhiming, Li Jianping Investigation and Reflection on School Mental Health Education (five) [J] China Education Daily, 1999 (1): 27. 